\title{
Four Year Cloud Attenuation Study in a Tropical Station
}

Publisher: IEEE

Cite This

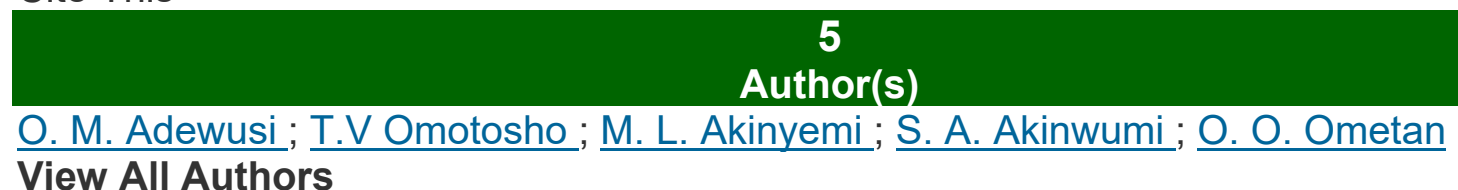

View All Authors

Abstract:

The paper present four year results of Cloud attenuation measurements carried out at Covenant University, Ota, Nigeria. The links operate at frequency of $12.245 \mathrm{GHz}$ and the cumulative distribution function for monthly Cloud attenuation have been estimated from the 4-year measured spectrum analyser data. The result of the visually measured Cloud and Satellite Cloud cover data are presented. The monthly variability shows that the highest cloud attenuation at the station occur in August, reaching a maximum of $3.96 \mathrm{~dB}$ for $0.01 \%$ of time; which corresponding to an average cloud cover of $89.86 \%$ and $75.36 \%$ by ground and satellite data respectively of which Nimbostratus (Ns) is average of $29.1 \%$. The lowest cloud attenuation at the station occur in September, with a value of $2.5 \mathrm{~dB}$ for $0.01 \%$ of time; corresponding to an average cloud cover of $90.3 \%$ and $77.26 \%$ by ground and satellite data respectively, of which Nimbostratus (Ns) is average of $28.9 \%$.

Published in: 2019 IEEE International Symposium on Antennas and Propagation and USNC-URSI Radio Science Meeting

Date of Conference: 7-12 July 2019

Date Added to IEEE Xplore: 31 October 2019

ISBN Information:

ISSN Information:

INSPEC Accession Number: 19114604

DOI: 10.1109/APUSNCURSINRSM.2019.8889375

Publisher: IEEE

Conference Location: Atlanta, GA, USA, USA

\section{Introduction}

Clouds are atmospheric suspension of light expansive bodies composed of water droplets and aggregates of tiny ice particles. They have absorptive, scattering and polarizing effects on electromagnetic waves passing through them. The cloud attenuation is due to absorption of propagating signals' energy by clouds constituent small water droplets. Cloud models are mathematical algorithms scientifically designed to predict the impact of cloud on propagating electromagnetic waves in the atmosphere based on empirical data [1, 2, 3, 4, $6, \&$ 8]. Figure 1 shows the experimental set up for the station at Covenant University Ota Nigeria. Currently, satellite communication unavailability in most tropical region such as southwest Nigeria is above the allowed 1\% outage [5], [7], [9]. At Ku band and above, the effects of clouds before and after rainfall is required to determine the effective transmissions margin [4]. Effective cloud attenuation data are needed to model the impact of cloud on 
radio wave propagation at tropical climatic zone and compared with the existing cloud models from temperate Climatic zones. Salonen model presented the algorithm for estimating amount of cloud liquid water as well as ice present in clouds, using radiosonde data [2], [7].

IGARSS 2003. 2003 IEEE International Geoscience and Remote Sensing Symposium. Proceedings (IEEE Cat. No.03CH37477)

Published: 2003

Multi-frequency radar Doppler spectrum measurements of cirrus clouds

IGARSS 2001. Scanning the Present and Resolving the Future. Proceedings. IEEE 2001 International Geoscience and Remote Sensing Symposium (Cat. No.01CH37217)

Published: 2001

Top Organizations with Patents on Technologies Mentioned in This Article

View More

A not-for-profit organization, IEEE is the world's largest technical professional organization dedicated to advancing technology for the benefit of humanity.

(c) Copyright 2020 IEEE - All rights reserved. Use of this web site signifies your agreement to the terms and conditions. 